\title{
Pin-on-Disc Study of Tribological Performance of Standard and Sintered Gear Materials Treated with Triboconditioning Process: Pre-treatment by Pressure-induced Tribo-film formation
}

\section{Xinmin Li, Ulf Olofsson \& Ellen Bergseth}

To cite this article: Xinmin Li, Ulf Olofsson \& Ellen Bergseth (2016): Pin-on-Disc Study of Tribological Performance of Standard and Sintered Gear Materials Treated with Triboconditioning Process: Pre-treatment by Pressure-induced Tribo-film formation, Tribology Transactions, DOI: 10.1080/10402004.2016.1146379

To link to this article: http://dx.doi.org/10.1080/10402004.2016.1146379

Accepted author version posted online: 04 Apr 2016.

Published online: 04 Apr 2016.

Submit your article to this journal ¿

山 Article views: 12

Q View related articles ¿

View Crossmark data \lceil 


\title{
ACCEPTED MANUSCRIPT
}

Pin-on-Disc Study of Tribological Performance of Standard and Sintered Gear Materials Treated with Triboconditioning Process: Pre-treatment by Pressure-induced Tribo-film formation

Xinmin Li, Ulf Olofsson

Department of Machine Design, Royal Institute of Technology (KTH) SE 10044, Stockholm, Sweden

\begin{abstract}
Coating is one of the innovative approaches used to improve the wear resistance and loadcarrying capacity of surfaces in rolling-sliding contact, such as gears and rolling element bearings. In this study, the tribological performance of standard gear material (EN 16MnCr5) and two kinds of powder metallurgy (PM) gear material (Distaloy AQ + 0.2\% C and Astaloy $85 \mathrm{Mo}+0.2 \% \mathrm{C}$ ) with and without tribofilms formed by a pre-treatment were evaluated. Specimens treated with the pre-treatment and the substrate is subjected to pin-on-disc tests under boundary lubrication conditions. The friction and wear performance of the two different PM gear materials with the pre-treatment formed tribo-film were compared to RS-RS (EN $16 \mathrm{MnCr} 5$ material disc and pin combination) for reference. It was found that the pre-treatment lowers the friction coefficient and enhances the wear resistance of pins because of the tribo-

film formed. The tribo-film caused good running-in due to the existing of $\mathbf{W S _ { 2 }}$ and $\mathrm{Fe}$ and $\mathrm{W}$ oxides. Mo-Mo (Astaloy $85 \mathrm{Mo}+0.2 \% \mathrm{C}$ material disc and pin combination) and Mo-RS (Astaloy $85 \mathrm{Mo}+0.2 \% \mathrm{C}$ disc and $\mathrm{EN} 16 \mathrm{MnCr} 5$ pin combination) showed statistically significant higher wear resistance.
\end{abstract}

Keywords: Gear material, Powder metallurgy, Pre-treatment, Wear, Friction 


\section{ACCEPTED MANUSCRIPT}

\section{INTRODUCTION}

Surface coating technology provides lower friction coefficients, higher load capacities, and higher protection against surface failures and is an important way to achieve improved tribological performance in gear transmissions (Almaro RI et al.(1); Moorthy and Shaw; (2); Jiang(3); Lu et al.(4)). Physical vapour deposition (PVD) using such coatings such as TiN, WC/C, and DLC (diamond-like carbon) provide low friction coefficients, good wear resistance, and heavy load-carrying capacities and are potential candidates as gear coatings (Kalin(5); Vera EE(6); Wänstrand(7)). By performing efficiency tests using a back-to-back FZG test rig, (Andersson et al. (8)) showed that PVD-coated gears lead to high efficiency. All these studies focus on the tribological properties of hard coatings in rolling-sliding contacts such as gears and rolling element bearings. The tribo-film formed using the triboconditioning process is softer and cheaper compared with these coatings, and is good for running-in (Zhmud (9)). (Heinrichs et al.(10)) investigated the influence of the triboconditioning process on three underlying substrates (Mahle E3224, EN Cf45 and EN-GJS-500-7) as well as the morphology and composition of the tribo-film formed. (Zhmud et al. (9)) showed that the triboconditioning process leads to a smoother surface with a significantly reduced coefficient of boundary friction and improved wear resistance and load-carrying capacity for rocker arm shafts, camshafts, and cylinder liners. It is noteworthy that the loads used in the tested conditions were in general lower than those common in high-performance rolling-sliding contacts such as gears. 


\section{ACCEPTED MANUSCRIPT}

Porosity influences the mechanical properties of sintered steels (Hoffmann (11); Fleck NA (12); Bocchini (13)). (Li et al. (14) used a pin-on-disc experiment to investigate the tribological properties of two different PM materials in boundary and mixed lubrication conditions simulating the contact conditions of the FZG gear test setup. A standard gear material and a PM gear material treated with the pre-treatment operating under contact conditions simulating a gear contact have not so far been studied in detail. In this study, the tribological performance of standard gear material (EN 16MnCr5) and two kinds of PM gear material (Distaloy AQ + 0.2\% $\mathrm{C}$ and Astaloy $85 \mathrm{Mo}+0.2 \% \mathrm{C}$ ) with and without the pre-treatment were evaluated by pin-ondisc experiment under boundary lubricated conditions. The objective is to determine whether the tribo-film formed in the pre-treatment can enhance certain tribological properties of the contact surfaces for further application in gear transmissions.

\section{EXPERIMENTAL SET-UP}

\section{Pin-on-Disc machine}

Pin-on-disc tester was used to study the characteristics of materials, lubricant and so on. Leonardo Israel Farfán-Cabrera et al.(15), Masoud Hashemi(16) and Akshay A. Joshi(17) studied the characteristics of lubricant, materials and coatings by doing pin-on-disc experiment respectively. A pin-on-disc machine was used to simulate the sliding part of a gear contact in this study. The configuration of the pin-on-disc machine is shown in Fig. 1. The pin-on-disc machine comprised a horizontal rotating disc and a calibrated deadweight-loaded pin. For these tests, the tip of the pin was a non-rotating half sphere with a radius of $5 \mathrm{~mm}$. The friction force and vertical displacement of the pin were automatically measured in the pin-on-disc machine 


\section{ACCEPTED MANUSCRIPT}

using a load cell and a linear variable differential transformer (LVDT). For all experiments, the maximum contact pressure was $1.08 \mathrm{GPa}$, which is the Maximum Hertzian contact pressure of load stage 7 in an FZG gear test rig (FZG Basic Training Documents (18)). Before the experiment, all specimens were cleaned in an ultrasonic bath, rinsed in heptane, then rinsed in methanol, and finally dried in an oven. A syringe with a brush continuously applied filtered ambient temperature lubricant with the aid of a pneumatic system. The lubricant is for heavy trucks with EP additives.

\section{The test specimens}

The pin and disc specimens were manufactured from three gear materials: one standard steel and two PM gear materials. The chemical composition of the materials is shown in Table 1. RS, AQ and Mo will be used in the remainder of this paper to identify the tested materials: EN 16MnCr5 (RS), Distaloy AQ + 0.2\% C (AQ) and Astaloy 85Mo + 0.2\%C. Both PM materials had the same density $\left(7200 \mathrm{Kg} / \mathbf{m}^{3}\right)$ and were sintered for 45 minutes at $1120^{\circ} \mathrm{C}$ in $90 \%$ nitrogen and $10 \%$ hydrogen atmosphere. The sintered materials are porous, and how they are manufactured determines their porosity and thus their density and mechanical properties. According to Beiss (19), the elastic properties of PM steel materials can be calculated using the following formulas:

$$
\begin{aligned}
& E=E_{o}\left(\rho / \rho_{o}\right)^{3.4} \\
& v=\left(\rho / \rho_{0}\right)^{0.16}\left(1-v_{0}\right)-1
\end{aligned}
$$




\section{ACCEPTED MANUSCRIPT}

where $\rho_{o}, E_{o}$, and $v_{o}$ are the density, Young's modulus, and Poisson's ratio, respectively, of solid steel. The mechanical parameters of the RS and the two PM materials calculated by equation (1) and (2) are presented in Table 2. Fig. 2 presents a photograph of the disc and pin samples used in the present experiments. All the specimens were case hardened. The tip of the pin is in the shape of half sphere with radius of $5 \mathrm{~mm}$. The lubricant used was BP Castrol Syntrans $75 \mathrm{~W}-80$. Table 3 shows the specifications of the lubricant. To simulate the sliding part of the contact correctly, the surface roughness of the disc and pin was close to that prescribed for gears in DIN quality level 5 (ISO (20)).

\section{Pre-treatment Process}

The triboconditioning process (pre-treatment) combines extreme pressure mechanical treatment of the component surface with a tribo-chemical deposition of a film based on tungsten disulphide. Fig. 3 shows the procedure for the pre-treatment. A tool is pressed and slid against the disc in the presence of a special process fluid. As the tool passes over the surface it triggers a tribo-chemical reaction within the process fluid which gradually deposits a tribo-film on the surface of the component. The pressure applied on the tool also leads to a burnishing effect as some of the asperities on the surface are reduced and the valleys are gradually filled with the compound. In this experiment only the disc was coated because it was difficult to apply the special procedure to the pin tip given its hemispherical shape.

Fig. 4 shows the 3D surface roughness and amplitude parameters Sa and Sz of RS material discs without and with the pre-treatment as representative. The results show that the surfaces 


\section{ACCEPTED MANUSCRIPT}

become slightly smoother after the pre-treatment. It should be the same for AQ and Mo material discs because the surface manufacture method is the same for all discs. Fig. 5 shows the porosity structure of AQ and Mo pins near the tip. The porosity is a natural part of PM materials. Note that there are lots of porosities both on the surface and in the bulk material; more information is available in [14]. Porosities on or near the surface influence the friction and wear coefficients [14]. The arrows in Fig. 5 indicate the pin surface. Fig. 6 shows the metallurgical microstructure of Mo and AQ materials. The microstructure of Mo consists of martensite. The AQ microstructure is martensite with some bainite and single austenite grains probably linked to the undissolved nickel.

\section{Test procedure}

Table 4 shows the pin-on-disc test matrix. A and B will be used in the remainder of this paper to identify different material combinations. A is the material of the disc, and B is the material of the pin. Each test was performed twice to ensure repeatability.

\section{Calculation of Friction and Wear Coefficients}

The friction coefficient was calculated from the measured friction force divided by the normal load exerted on the pin by the testing machine's deadweight. Archard's wear model was used to calculate the wear coefficient:

$$
\frac{V}{S}=K N
$$




\section{ACCEPTED MANUSCRIPT}

where $V$ is the volume loss in $\mathrm{m}^{3}$ on the contact surface of pins. $S$ is the sliding distance in $\mathrm{m}, K$ is the specific wear coefficient $\left(\frac{m^{2}}{N}\right)$, and $N$ is the normal load in N. Reformulating this gives:

$$
K=\frac{V}{N S}
$$

The wear scar diameter was measured using optical microscopy in the ordinate and abscissa directions at the end of each test. The volume removed from the pin surface can then be calculated using the following method. The main parameters used in calculating the volume loss are shown in Fig. 7. The volume loss, $V$, of the pin, which is half spherical in shape, is calculated by:

$$
V=\pi h^{2}\left(r-\frac{h}{3}\right)
$$

Where $d$ is the diameter of the wear scar, $r$ is the radius of the half sphere, and $h$ is the height of the wear volume, which can be calculated as:

$$
h=r-\left(r^{2}-\left(\frac{d}{2}\right)^{2}\right)^{\frac{2}{2}}
$$

Note that the height of wear scar was also measured by LVDT of pin-on-disc equipment. But for lubricated contact the height of it is usually from around 2 to $4 \mu \mathrm{m}$. The deviation of LVDT $(0.2 \mu \mathrm{m})$ and the heat expand of materials should influence the results of LVDT greatly. So usually the height of wear scar of pin is calculated and the same method was adapted by $\mathrm{Li}$ (14) and Damoon Sohrabi Baba Heidary (21).

\section{GD-OES measurement}




\section{ACCEPTED MANUSCRIPT}

The parts of disc samples both with and without the pre-treatment were analysed by glow discharge optical emission spectroscopy (GD-OES) in order to determine the chemical components of the coating (Bengtson (22)). The sample forms the cathode in a low-pressure glow discharge lamp (GDL), designed for spectral analysis of flat samples.

The sample seals against a $12 \mathrm{~mm}$ O-ring on the lamp front. Positively charged argon ions strike the sample surface, which is typically sputtered at a rate of $20-100 \mathrm{~nm} / \mathrm{s}$. The sputtered material is atomized and diffuses into the plasma, where the atoms are electronically excited and emit element-specific optical emissions. The emissions are recorded as a function of time by a multichannel optical spectrometer with a maximum sampling frequency of $300 \mathrm{~Hz}$. This provides time-intensity elemental depth profiles. This test methodology has been previously used to evaluate environmentally adapted lubricants by Bergseth et al., (23), biological layers on rails Olofsson (24) and roller bearing lubricants by Olofsson and Dizdar (25).

\section{Surface analysis}

After the test, the tested specimens were measured using a Taylor Hobson Form Talysurf with tip radius of $2 \mu \mathrm{m}$ to determine the surface roughness and amplitude parameters of the contacting part of the pin and disc specimen. A micro-hardness tester (Matsuzawa MMT-7) was used to determine the hardness profiles of the pin and disc specimens. The metallurgical microstructure of the pins was also examined to study the metallurgical difference between AQ and Mo. 


\section{ACCEPTED MANUSCRIPT}

\section{ANOVA analysis}

Analysis of variance, or ANOVA (Andersson (26)), was used to determine whether there was a statistically significant difference between the samples. We used the function Anova2(X, 1) in Matlab for a two-factor (material combination and pre-treatment used or not) analysis of variance. $\mathrm{X}$ is a matrix with two columns (Wear or friction coefficient data of substrate and disc with pre-treatment) and six rows (six different material combinations). After solving the wear/friction coefficient data by Anova2 $(X, 1)$, we obtain two $p$ values: $p_{T}$ is the $p$ value of the pre-treatment, and $p_{m}$ is the $p$ value of material combination. By determining whether $p_{T}$ or $p_{m}<0.05$, we can judge whether the pre-treatment or the material combination has a statistically significant effect on wear and friction.

\section{RESULTS}

\section{Surface Analysis}

Hardness measurements were made near the tip of the new pin specimens $\left(H V_{0,1}\right)$. The hardness-depth curve shown in Fig. 8 indicates that the RS material is harder than both the AQ and the Mo material. In addition, the Mo material is harder than the AQ material above a depth of $0.5 \mathrm{~mm}$. The hardness of AQ, Mo, and RS pins decreases with increasing depth. At the meantime, the hardness of discs was measured and the results were shown in Table 5. The main wear is happened on pins (will be explained in details later), so just the hardness of disc surface is measured instead of the hardness-depth curve. Fig. 9 shows the 3D surface roughness of the worn pin tips. Again the pins combined with discs treated with pre-treatment have smoother surfaces than the others. Fig. 9 from (a') to (f') shows somewhat smoother 


\section{ACCEPTED MANUSCRIPT}

surfaces than (a) to (f). To analyse the surface roughness differences after experiment, the pin contact surfaces were also characterized by amplitude parameters $S_{a}$ and $S_{z}$ as shown in Table 6. Fig. 10 shows the $3 \mathrm{D}$ surface roughness and $2 \mathrm{D}$ profile of some wear tracks as representatives on the discs. Fig. 11 shows the micrographs of some wear tracks on disc as representatives. From 3D surface roughness and 2D profile of wear tracks we can not see wear tracks clearly on the disc. As shown in Fig. 11, we can see wear tracks clearly but the tracks left by manufacture method is heavier and most parts of tribo-film was worn off after the experiment. So in lubricated pin on disc experiment wear on the disc can be neglected.

\section{Wear results}

Table 7 shows the diameter of the wear scar of worn pin tip. The wear scars of pins are usually a circle. The diameter is the average value of the diameters in two vertical directions. The experiment was repeated for two times so the diameters are shown as first and second time values. The wear coefficient results are calculated as described in 2.4.2 and presented in Fig. 12 as mean values and standard deviations for the different test conditions (Table 4). For the same disc and pin material combinations, pins combined with discs treated with the pre-treatment always have lower wear coefficient. The low wear coefficient for the tests with Mo pins in contact with Mo discs is also noticeable.

\section{Friction results}

To obtain an overview of the test results, we present the mean values with standard deviation of all the tests in Fig. 13. The pins combined with discs subjected to pre-treatment show somewhat lower friction coefficients than the untreated cases. Since the pre-treatment is 


\section{ACCEPTED MANUSCRIPT}

designed for good running-in, the friction coefficients for the first five minutes, first stage (the first hour) and the last stage (the last hour) are also shown in terms of mean value and standard deviation in Fig. 14. This shows a clear running-in tendency for all tested combinations, but the change in friction coefficient is less dramatic for materials treated with the pre-treatment.

\section{Chemical composition of the tribofilm formed by the pre-treatment}

Fig. 15 compares the chemical composition of the tribo-film formed by the pre-treatment and the substrate. The GD-OES analysis was limited to iron, oxygen, carbide, sulphur, and tungsten. The percentage of sulphur is multiplied by five in order to better show the difference before and after pre-treatment. The obvious difference is that after the pre-treatment there is much more tungsten and sulphur than is present in the substrate. From Fig. 15 we can infer that the thickness of the tribo-film is 80 to $100 \mathrm{~nm}$. Zhmud $(27,28)$ studied the elemental composition of the tribofilms generated by the triboconditioning process by X-ray photoelectron spectroscopy and energy dispersive X-ray spectroscopy which had the same results as shown in Fig. 15.

\section{ANOVA analysis results}

The values $p_{T}$ and $p_{m}$ are derived from the wear coefficient, friction coefficient and surface amplitude parameters of pin respectively. Table 8 shows the ANOVA results of all the data. Table 8 The ANOVA results of wear coefficients, friction coefficients and pin surface amplitude parameters $S_{a}$ and $S_{z}$. 


\section{ACCEPTED MANUSCRIPT}

\section{DISCUSSION}

\section{Wear discussion--effect of the pre-treatment on wear}

The wear results in Fig. 12 show that pins run against discs treated with pre-treatment almost always have a lower wear coefficient than pins run against the same pin and disc material that has not been treated. This agrees with the trend presented in [9]. The improved wear is closely related to the pre-treatment. Pre-treatment combines extreme pressure mechanical burnishing with tribo-chemical deposition of a friction and wear-reducing compound on the component surface. As shown in Fig. 4a and b, the applied pressure leads to a burnishing effect as some of the asperities on the surface are levelled off and the valleys gradually filled with the frictionreducing compound. The smoother surface provide conditions for better running-in, which is good for both friction and wear in the stable stage, as is manifested by the 3D surface roughness of pins. Tables 8 showed the p values for both $S_{a}$ and $S_{z}$. For $S_{a} p_{T}=0.003, p_{m}=$ 0.38 and for $S_{z} p_{T}=0.018$, and $p_{m}=0.212$. Both $p_{T}$ values of $S_{a}$ and $S_{z}$ are less than 0.05 . This shows that the pre-treatment has a statistically significant effect on the surface amplitude parameters, but the material combination has no effect on the surface amplitude. Figs. $4 \mathrm{a}$ and $\mathrm{b}$ showed that the pre-treatment made the treated surface of disc smoother than that of the substrate disc. As shown in Fig. 9 and Table 6, the surface of pins combined with discs with pre-treatment is always smoother than that of substrate pins. So the extreme pressure burnishing of pre-treatment is one of the factors enhances the wear resistance of pins.

The GD-OES measurement showed that the tribo-film contained Fe, O, W, S, and some C. Previous studies by Podgornik et al. (Podgornik(29); Podgornik(30); Podgornik(31)) have 


\section{ACCEPTED MANUSCRIPT}

shown that a low friction reaction film, a tribo-film $W S_{2}$, can form on steel surfaces during sliding, when used in a sulphur and tungsten rich environment. The pre-treatment method used mineral oil carrying tungsten source by sorgano-tungstates and sulphur source by organicpolysulfides (Zhmud (32)), so that can undergo the following transformations in the tribocontact between the tool and the disc.

$$
\begin{aligned}
& R S_{n} R^{r}+F_{\theta} \rightarrow F_{e} S+R R^{r} \\
& W O_{3}+F_{e} \rightarrow F_{e} W O_{3} \\
& F_{e} W O_{3}+F_{e} S \rightarrow W S_{2}+F_{e} O
\end{aligned}
$$

$\mathrm{R}$ and $R^{r}$ stands for an organic radical, such as alkyl or aryl. That is to say the pre-treatment results in the formation of a tribo-film of 80-100 nm thick composed of tungsten, iron, oxygen, sulphur and carbon as shown in Fig. 15. So there should be some $\mathbf{W} \mathbf{S}_{2}$ in the tribofilm. $\mathbf{W} \mathbf{S}_{2}$ has a lamellar structure, analogous to graphite and $\mathrm{MoS}_{2}$, and is an efficient solid lubricant for both friction and wear. Fig. 15 showed that the tribo-film is mainly composed of Fe, O, and W, with minor $\mathrm{C}$ and $\mathrm{S}$ (around 6\%), which means the amount of $\mathbf{W} \mathbf{S}_{2}$ cannot be high. (Erdemir (33)) showed that Fe and W oxides may offer more easily sheared surface layers. So, even in cases where the amount of $\mathrm{WS}_{2}$ is not high, the tribofilm contains $\mathrm{Fe}$ and $\mathrm{W}$ oxides, which may also offer more easily sheared surface layers than the untreated steel. The easily sheared layers composed of $\mathbf{W} \mathbf{S}_{2}, \mathrm{Fe}$, and W oxides act as a solid lubricant, which can enable good runningin. The existence of these oxides could be another reason for the higher wear resistance of pins sliding on discs treated by pre-treatment. The beneficial effect of the tribo-film in regard to wear resistance and running-in suggests that the pre-treatment can be applied in gear transmissions. Further study will be performed in a gear wear experiment. 


\section{ACCEPTED MANUSCRIPT}

\section{The influence of materials and material combinations on wear}

As shown in Fig. 8, the Mo pins always have higher wear resistance than the AQ pins. This may be due to the higher hardness of Mo and its microstructure. Given that higher hardness usually implies higher wear resistance, the higher wear resistance of Mo is understandable. Fig. 6 shows the microstructure of pins of Mo and AQ. The Mo microstructure consists of martensite. In the case of the AQ, the microstructure consists of martensite with elements of bainite and austenite grain, probably linked occasionally to undissolved nickel. Martensite have higher hardness and wear resistance than austenite and banite. So pins of Mo have higher wear resistance than those of AQ mainly because of the martensite microstructure caused higher hardness. The RS-RS material combinations always showed higher wear coefficients than the AQ-RS and Mo-RS combinations. As different material combinations can prevent adhesive wear (Beek (34)). This is probably why the RS-RS combination always shows higher wear coefficients than AQ-RS and Mo-RS. The same is true for the pins of AQ-AQ and RS-AQ combination.

The high wear resistance of Mo-Mo and Mo-RS suggests that they might be used in gear transmissions, subject to further studies in full-scale gear tests such as those using an FZG machine.

\section{The influence of the pre-treatment on friction}




\section{ACCEPTED MANUSCRIPT}

Table 8 shows the results of applying the anova 2 function to the friction coefficient data of the whole experiment (Fig. 13): $p_{T}=0.004 \ll 0.05, p_{m}=0.59$. Thus the pre-treatment has directly influenced the friction coefficient, but the material combination has little effect. Fig. 13 shows that the friction coefficients of pins combined with discs treated with the pre-treatment exhibit somewhat lower friction coefficients than the others, independent of material combinations. In order to determine the friction mechanism, the friction coefficient of the first five minutes, the first hour stage and the last hour stage are also shown in Fig. 14. The ANOVA results of them are shown in Tables 8 .

As shown in Fig. 14 for the first five minutes, first and last stages, the friction coefficients of discs with the pre-treatment are always lower than those of discs without pre-treatment. The related $p_{T}$ values are $0.0148,0.0165$, and 0.005 respectively as shown in Tables 8 . As they are all far less than 0.05 , the pre-treatment process has had a statistically significant effect in reducing the friction coefficient in all stages of the experiment. The smoother surface (compare Fig. 4a and b) caused by the high pressure and the formation of $\mathbf{W S}_{2}$ and Fe and $\mathrm{W}$ oxides contributes to the lower friction coefficient of pins combined with discs treated by the pretreatment in the first five minutes and the first stage. Smoother surfaces always lead to a lower friction coefficient. For the last stage, the lower friction coefficient of pins combined with discs with the pre-treatment is due to the good running-in caused smoother surface of the pins. As shown in Fig. 9 and Table 6, surfaces of pins combined with discs treated with the pretreatment are always smoother than those with only the substrate combination. 


\section{ACCEPTED MANUSCRIPT}

\section{CONCLUSION}

The sliding part of a gear tooth contact was simulated in pin-on-disc experiments. The friction properties and wear resistance of two PM steel gear materials and a regular steel gear material with and without pre-treatment were investigated and compared. The following conclusions can be drawn from this study:

- The pre-treatment enhances the wear resistance and lowers the friction coefficient of pins because of the formation of $\mathrm{WS}_{2}, \mathrm{Fe}$ and $\mathrm{W}$ oxides enabled good running-in and the brushing effect enabled smoother surface.

- Mo-Mo and Mo-RS combinations show statistically significant higher wear resistance compared to RS-RS and can be used in further gear transmission studies.

\section{ACKNOWLEDGEMENTS}

Thanks are expressed to Dr Michael Andersson and Engineer Marcus Persson from Höganäs $\mathrm{AB}$ for their guidance and technological support. This project was financially supported by Höganäs AB. The pre-treatment was performed by ANS.

\section{REFERENCE}

(1) Almaro RI et al. Carbon/chromium low friction surface coating for gears application, Ind Lubr. Tribol. 2005; 57(6): 233-242, http://dx.doi.org/10.1108/00368790510622326 


\section{ACCEPTED MANUSCRIPT}

(2) Moorthy V, Shaw BA. Contact fatigue performance of helical gears with surface coatings. Wear 2012; 276-277: 130-140.

(3) Jiang JC, Meng WJ, Evans AG, Coope, CV. Structure and mechanics of W-DLC coated spur gears. Surface and Coatings Technology, 176(1): 50-56.

(4) Lu et al. Characteristic evaluation of friction and wear in the $\mathrm{C}-\mathrm{N}$ and TiN coated gear. International Journal of Precision Engineering and Manufacturing 2010; 11(1): 107-111. (5) Kalin M, Vižintin J. The tribological performance of DLC-coated gears lubricated with biodegradable oil in various pinion/gear material combinations. Wear 2005; 259(7): 12701280.

(6) Vera EE, Vite M, Lewis R, Gallardo EA, Laguna-Camacho JR, A study of the wear performance of TiN, CrN and WC/C coatings on different steel substrates, Wear 2011; 271(9): $2116-2124$.

(7) Wänstrand O, Larsson M, Hedenqvist P. Mechanical and tribological evaluation of PVD WC/C coatings. Surf Coat Technol 1999; 111(2): 247-254.

(8) Andersson M, Björklund S, Sellgren U, Olofsson U., A study of the influence of gear surface roughness and immersion depth on gear efficiency and temperature, 16th Nordic Symposium on Tribology, Århus, Denmark 2014.

(9) Zhmud B, Åkerlund E, Jacobson S, Hardell J, Hammerström L, Ohlsson R. ANS Triboconditioning: In-manufacture running-in process for improving tribological properties of mechanical parts made of steel or cast iron, Proc. 18th International Colloquium Tribology Industrial and Automotive Lubrication, 10-12 January 2012, TAE, Ostfildern, Germany. 


\section{ACCEPTED MANUSCRIPT}

(10) Heinrichs J, Jenei IZ, Jacobson S. Morphology and composition of tribofilms deposited using tribochemical burnishing technique. Tribology - Materials, Surfaces \& Interfaces 2014; 8(1):14-20, http://dx.doi.org/10.1179/1751584X14Y.0000000069

(11) Hoffmann G, Sonsino CM, Michaelis K. Rolling contact fatigue: Component design and testing for P/M applications, Society of Automotive Engineers, 1999.

(12) Fleck NA, Smith RA. Powder Metall 1981; 3: 121-125.

(13) Bocchini G. Int. J. Powder Metall 1986; 22: 185-202.

(14) Li X, et al. A pin-on-disc study of the tribology characteristics of sintered versus standard steel gear materials. Wear 2015, http://dx.doi.org/10.1016/j.wear.2015.01.032i

(15) Leonardo Israel Farfán-Cabrera, Ezequiel Alberto Gallardo-Hernández, Manuel Vite-Torres \& Juan Rodrigo Laguna-Camacho (2015) Frictional Behavior of a Wet Clutch Using Blends of Automatic Transmission Fluid (ATF) and Biolubricant (Jatropha Oil) in a Pin-on-Disk Tester, Tribology Transactions, 58:5, 941-946,

DOI:10.1080/10402004.2015.1032461

(16) Masoud Hashemi (2015) Microstructure and Wear Behavior of a Manganese Bronze Bearing Material under Unlubricated Conditions, Tribology Transactions, 58:4, 750-757, DOI: $10.1080 / 10402004.2015 .1015756$

(17) Akshay A. Joshi, Santosh S. Hosmani \& Jayshri Dumbre (2015) Tribological Performance of Boronized, Nitrided, and Normalized AISI 4140 Steel against Hydrogenated Diamond-Like Carbon-Coated AISI D2 Steel, Tribology Transactions, 58:3, 500-510, DOI: $10.1080 / 10402004.2014 .988377$

(18) FZG Basic Training Documents, Strama-MPS Maschinenbau GmbH \& Co. KG. 


\section{ACCEPTED MANUSCRIPT}

(19) Beiss P. Mechanische eigenschaften von sinterstählen. Tagungsband zum Symposium für Pulvermetallurgie: Material-Prozess-Anwendung Hagen 2003; 27.

(20) ISO 1328-2:1997(E).

(21) Damoon Sohrabi Baba Heidary, Farhad Madadi \& Morteza Shamanian (2015) Study of the Microstructures and Abrasive Characteristics of Mo-Fe-C Hardfacing Alloys Fabricated by Gas Tungsten Arc Welding, Tribology Transactions, 58:2, 225-230, DOI:

10.1080/10402004.2014. 963771

(22) Bengtson A, Quantitative depth profile analysis by glow discharge. Spectrochimica Acta Part B 1994; 49: 411-429.

(23) Bergseth E, Torbacke M, Olofsson U. Wear in environmentally adapted lubricants with AW/EP technology. Journal of Synthetic Lubrication 2008; 25(4): 137-158.

(24) Olofsson U, A multi-layer model of low adhesion between railway wheel and rail. Proc IMechE Part F: J Rail and Rapid Transit 2007; 221: 385 - 389.

(25) Olofsson U, Dizdar S. Surface analysis of boundary lubricated spherical roller thrust bearings. Wear 1997; 215: 156-164.

(26) Andersson Ö. Experiment! Planning, implementing and interpreting. Chichester: John Wiley; 2012, p 155-159.

(27) Zhmud B., Tomanik E., Xavier F.-A., Tribology, Surface Chemistry and Morphology of WS2 Tribofilms Generated by the ANS Triboconditioning Process, Lubrication Science 26 (2014) 277. 


\section{ACCEPTED MANUSCRIPT}

(28) Zhmud B., Berg M., Tribology, Surface Chemistry and Morphology of WS2 Tribofilms Generated by the ANS Triboconditioning Process, in Proc. 19th Int. Colloquium Tribology Industrial and Automotive Lubrication, 21-23 January 2014, Stuttgart, Germany.

(29) Podgornik B., Hren D., Vižintin J., Jacobson S., Stavlid N., Hogmark S., Combination of DLC coatings and EP additives for improved tribological behaviour of boundary lubricated surfaces, Wear, Volume 261, Issue 1, 20 July 2006, Pages 32-40.

(30) Podgornik B., Vižintin J., Jacobson S., Hogmark S., Tribological behaviour of WC/C coatings operating under different lubrication regimes, Surface and Coatings Technology, Volume 177-178, 30 January 2004, Pages 558-565.

(31) Podgornik B., Jacobson S., Hogmark S., Influence of EP and AW additives on the tribological behaviour of hard low friction coatings, Surface and Coatings Technology, Volume 165, Issue 2, 10 February 2003, Pages 168-175.

(32) Zhmud B., Method for providing a low-friction surface, Stockholm, Sweden, 20130104357, 2013-05-02

(33) Erdemir A. A crystal-chemical approach to lubrication by solid oxides. Tribology Letters 2000; 8(2-3): 97-102.

(34) Beek A. van, Advanced engineering design: Lifetime performance and reliability. 2009; p $155-158$. 


\section{ACCEPTED MANUSCRIPT}

NOMENCLATURE

$\begin{array}{llll}\text { PM } & \text { Powder Metallurgy } & \rho, \rho_{o} & \text { Density } \\ \text { RS } & \text { EN 16MnCr5 } & \text { E, } E_{o} & \text { Young's modulus, Gpa } \\ \text { AQ } & \text { Distaloy AQ+0.2\%C } & v, v_{o} & \text { Poisson's ratio } \\ \text { Mo } & \text { Astoloy 85Mo +0.2\% C } & \alpha & \text { Pressure viscosity coefficient, }\left(\mathbf{P a}^{-1}\right) \\ \eta & \text { Dynamic viscosity, (Pas) } & \mathrm{V} & \text { volume loss, } \mathrm{m}^{3} \\ \mathrm{~A}-\mathrm{B} & \text { disc-pin } & \mathrm{T} & \text { Time, } \mathrm{s} \\ \mathrm{N} & \text { Load, } \mathrm{N} & \mathrm{S} & \text { Sliding distance, } \mathrm{m}\end{array}$




\section{ACCEPTED MANUSCRIPT}
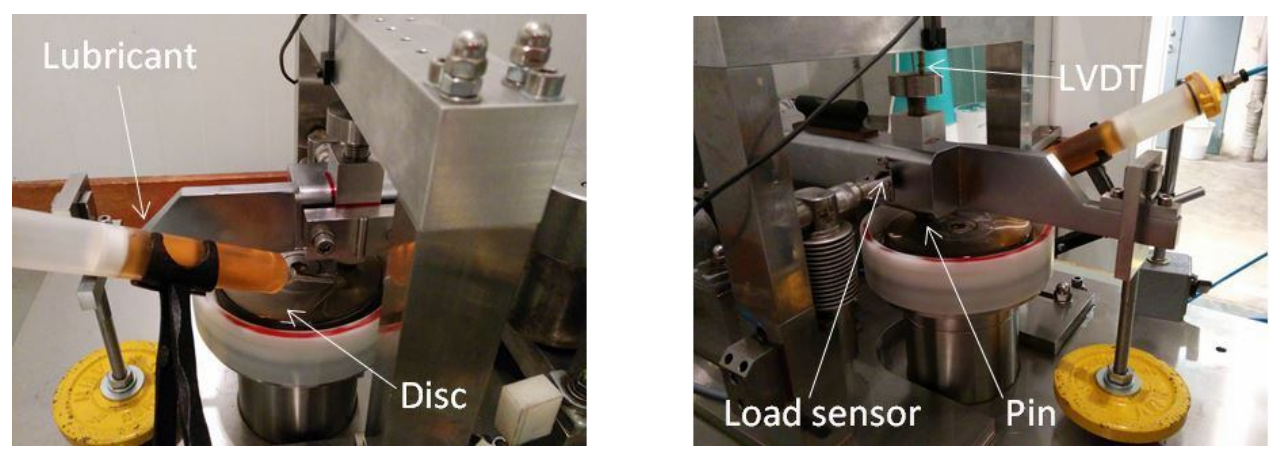

Fig. 1 Configuration of pin-on-disc machine 


\section{ACCEPTED MANUSCRIPT}

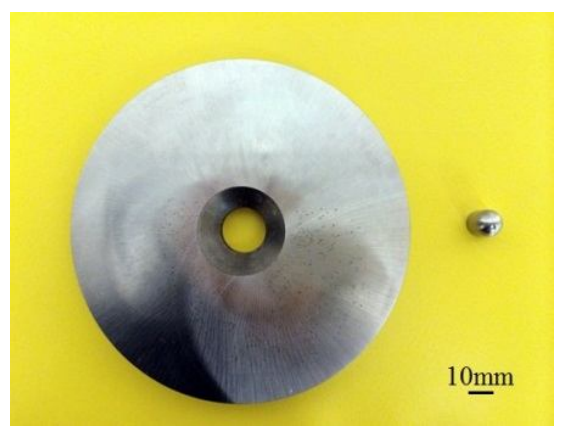

Fig. 2 Disc and pin specimens 


\section{ACCEPTED MANUSCRIPT}

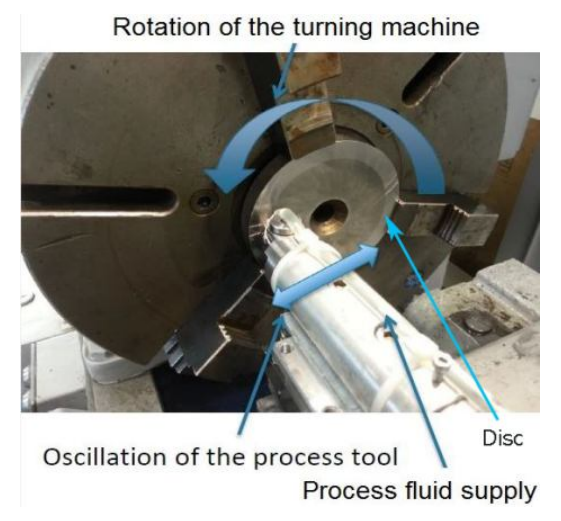

Fig. 3 Procedure for the pre-treatment 


\section{ACCEPTED MANUSCRIPT}

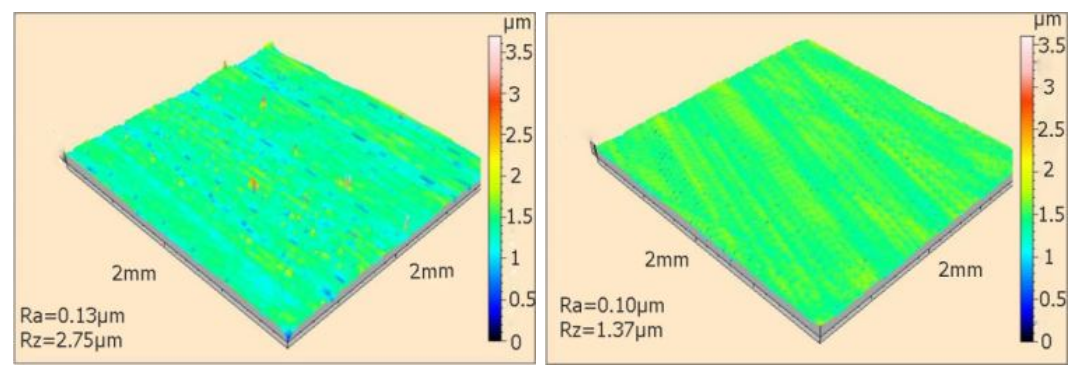

(a)

(b)

Fig. 4 3D surface roughness of RS material discs (a) substrate, (b) after the pre-treatment 


\section{ACCEPTED MANUSCRIPT}

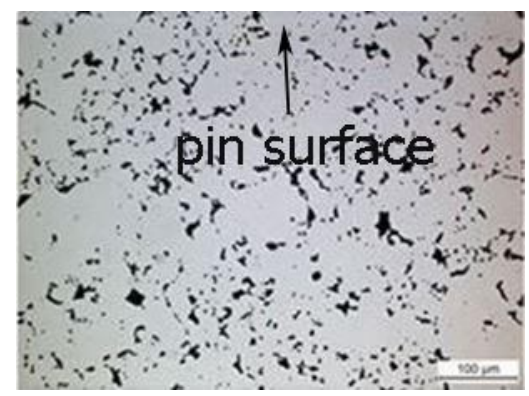

(a)

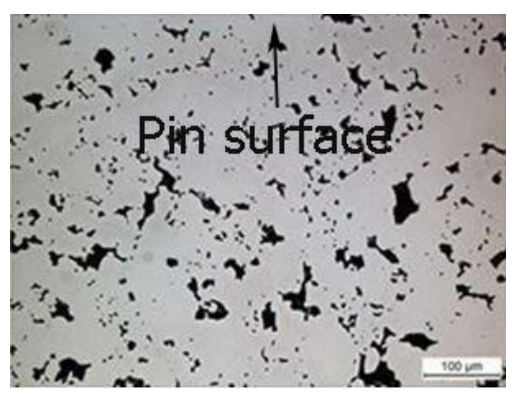

(b)

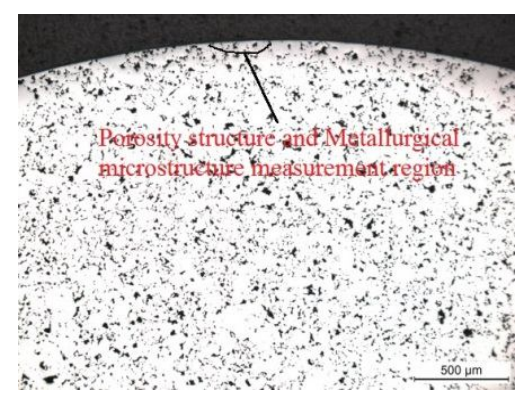

(c)

Fig. 5 Porosity structure of AQ (a), Mo (b) pins and (c) porosity structure and metallurgical microstructure measurement region. 


\section{ACCEPTED MANUSCRIPT}

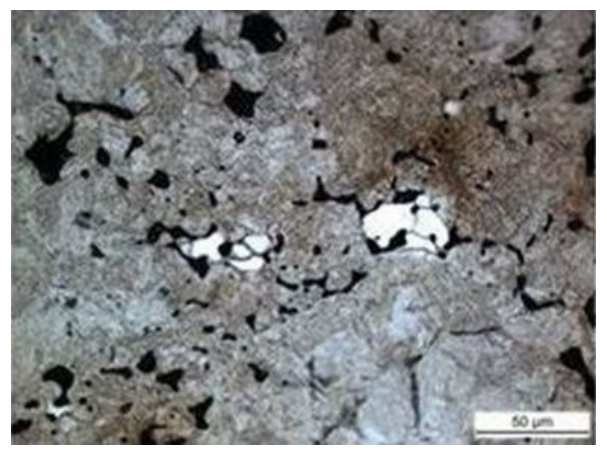

(a)

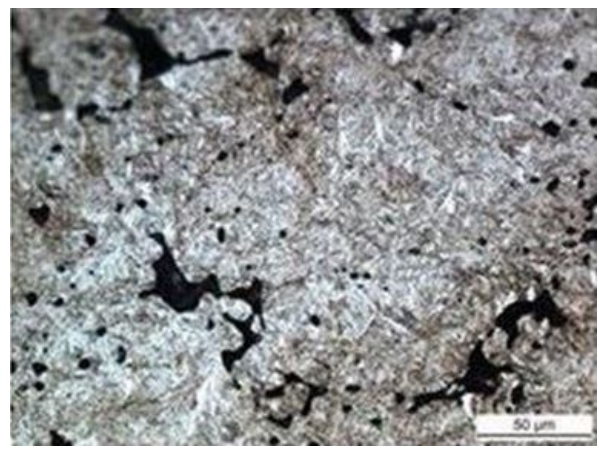

(b)

Fig. 6 Metallurgical microstructure of AQ (a) and Mo (b) pins 


\section{ACCEPTED MANUSCRIPT}

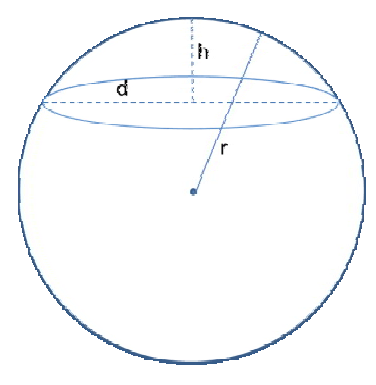

Fig. 7 The wear scar. 


\section{ACCEPTED MANUSCRIPT}

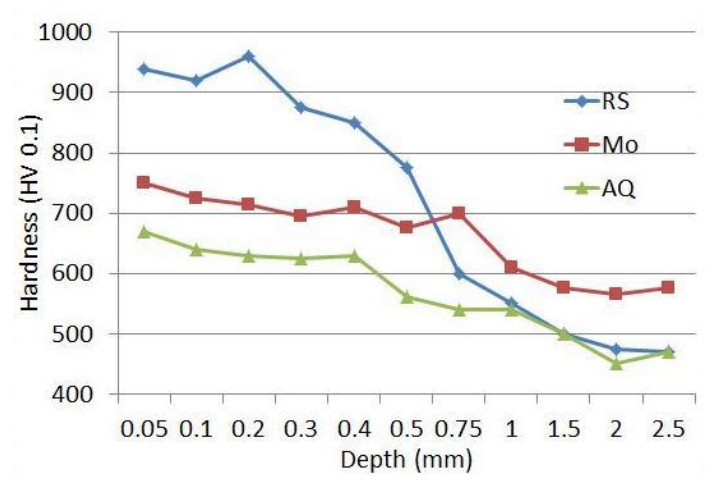

Fig. 8 Hardness-depth curve of RS, Mo, and AQ pin tip 


\section{ACCEPTED MANUSCRIPT}

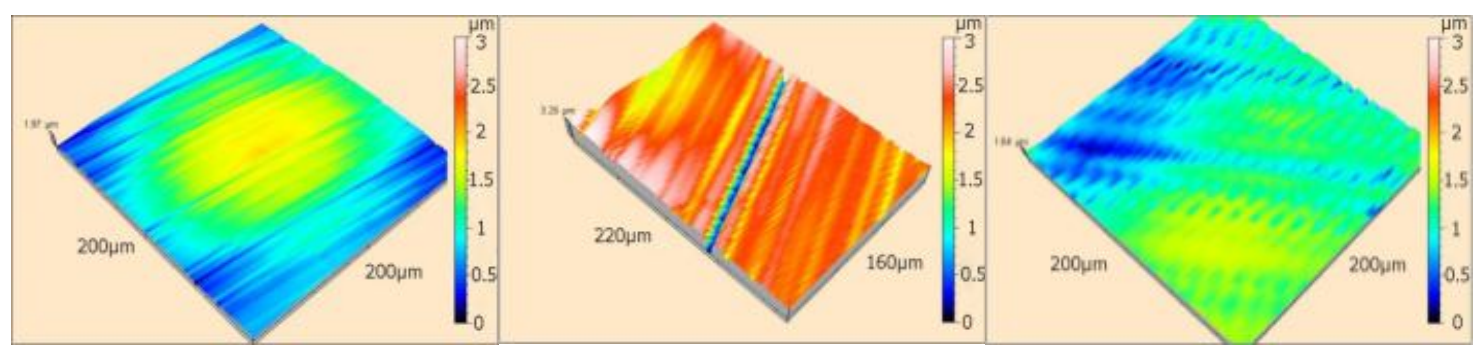

(a) RS-RS

(b) AQ-RS

(c) Mo-RS

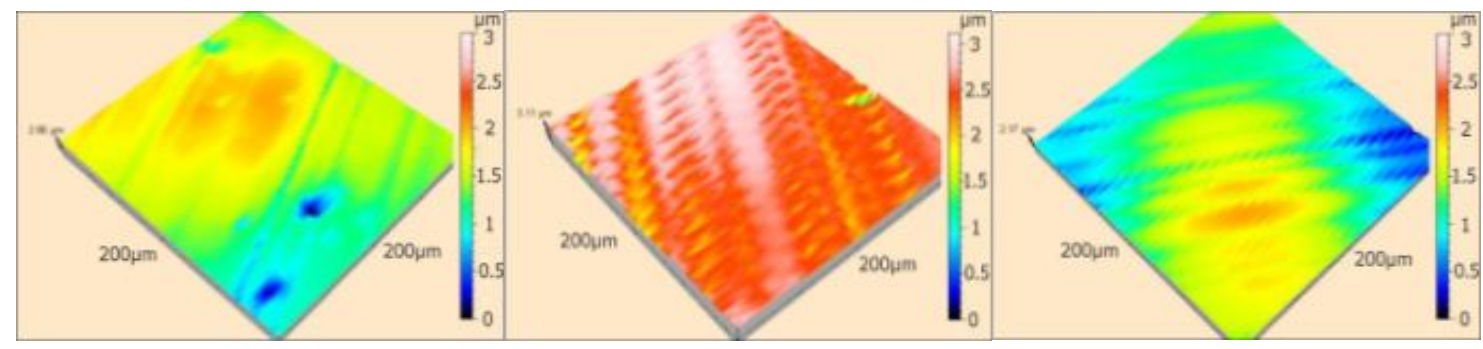

(d) Mo-Mo

(e) AQ-AQ

(f) RS-AQ

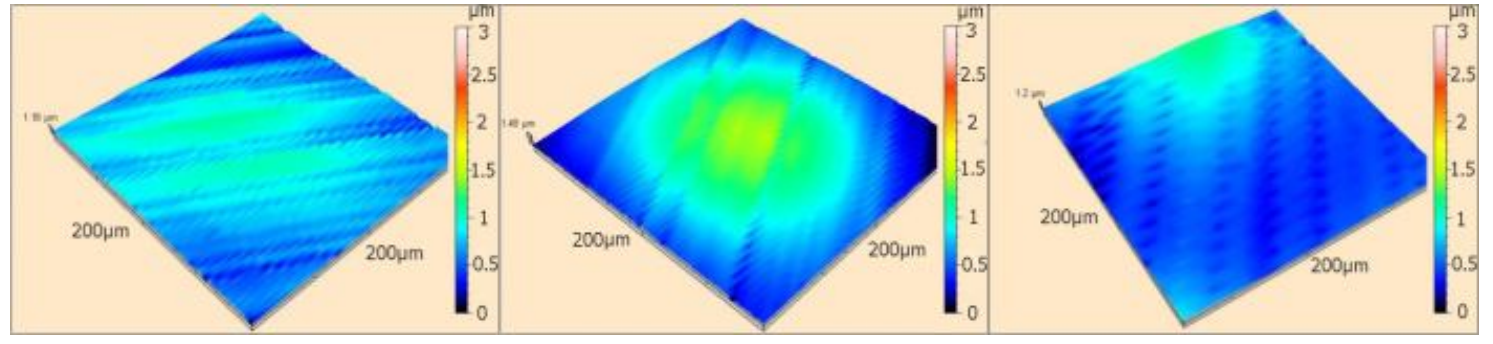

(a') RS-RS

(b') AQ-RS

(c') Mo-RS

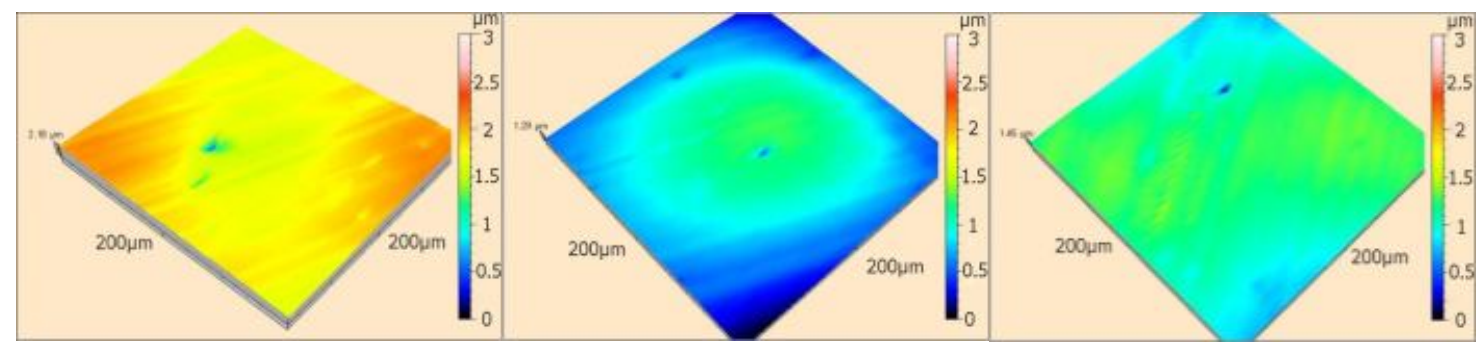

(d') Mo-Mo

(e') AQ-AQ

(f') RS-AQ

Fig. 9 3D surface roughness of the worn pin tip, a-f: sliding on disc without pre-treatment; a'-

f': sliding on disc with pre-treatment 


\section{ACCEPTED MANUSCRIPT}

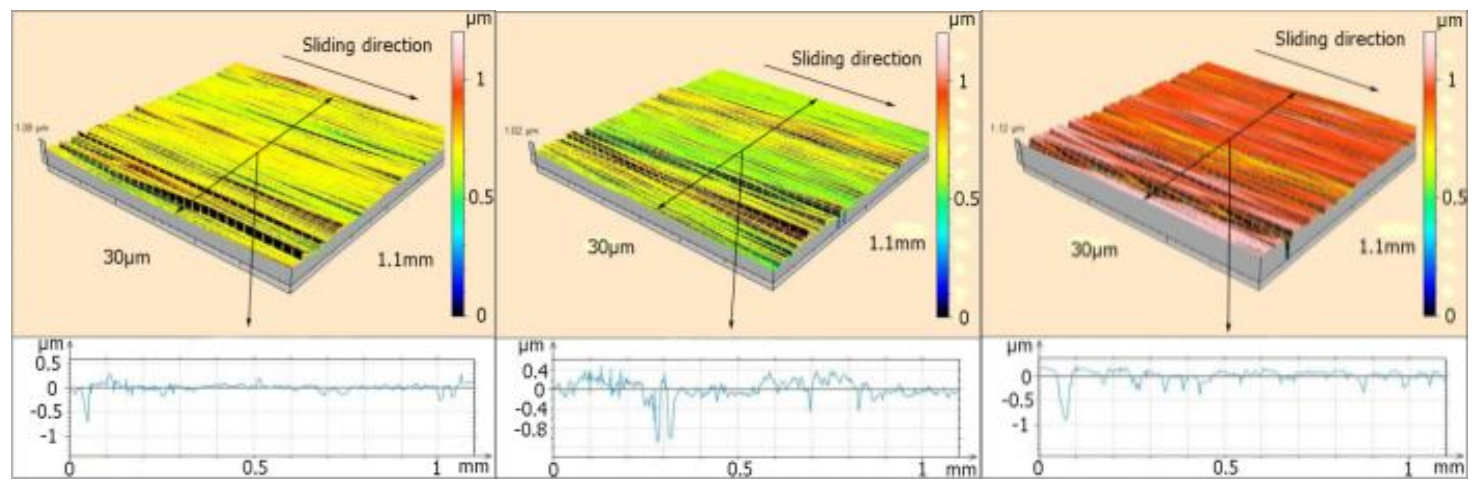

(a) RS-RS

(b) AQ-RS

(c) Mo-RS
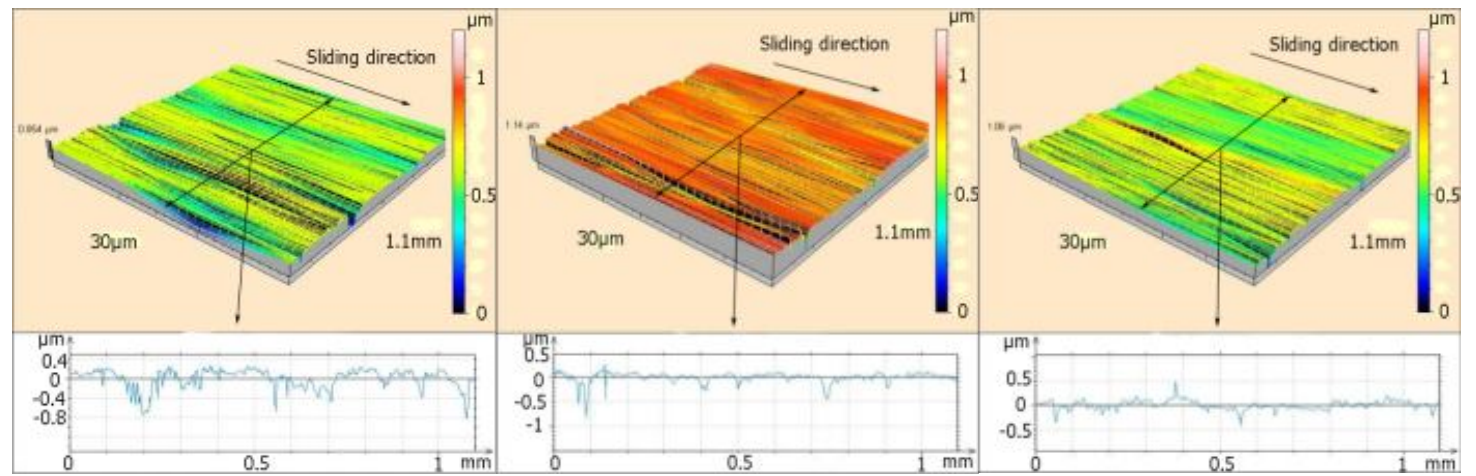

(a') Mo-Mo

(b') AQ-AQ

(c') RS-AQ

Fig. $103 D$ surface roughness $2 \mathrm{D}$ profile of wear tracks on the disc. (a, b, c: disc without pretreatment; a', b', c': disc with pre-treatment) 


\section{ACCEPTED MANUSCRIPT}

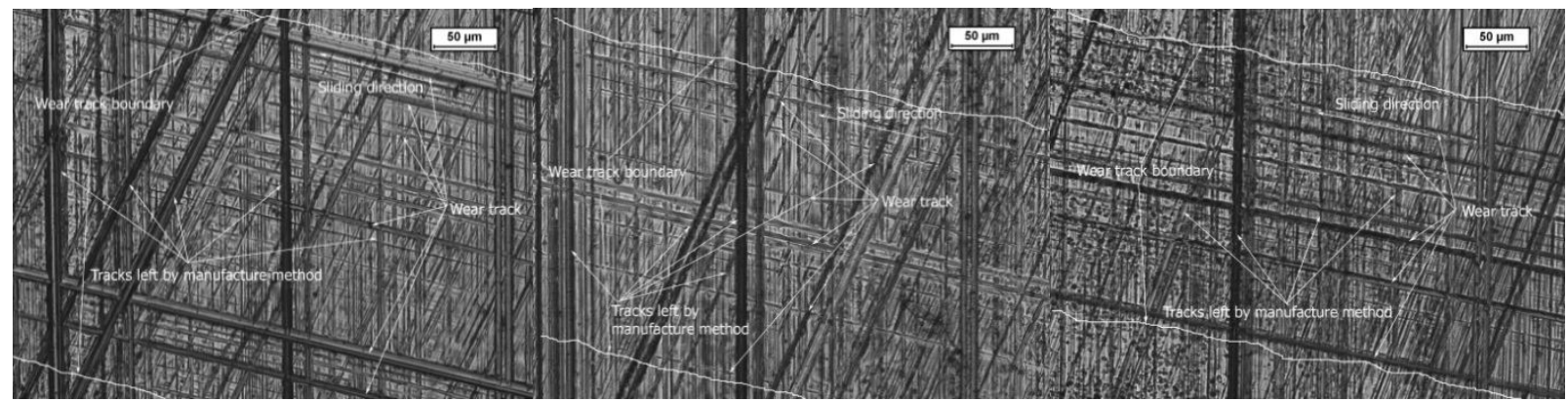

(a) $\mathrm{AQ}-\mathrm{AQ}$

(b) RS-RS

(c) Mo-Mo

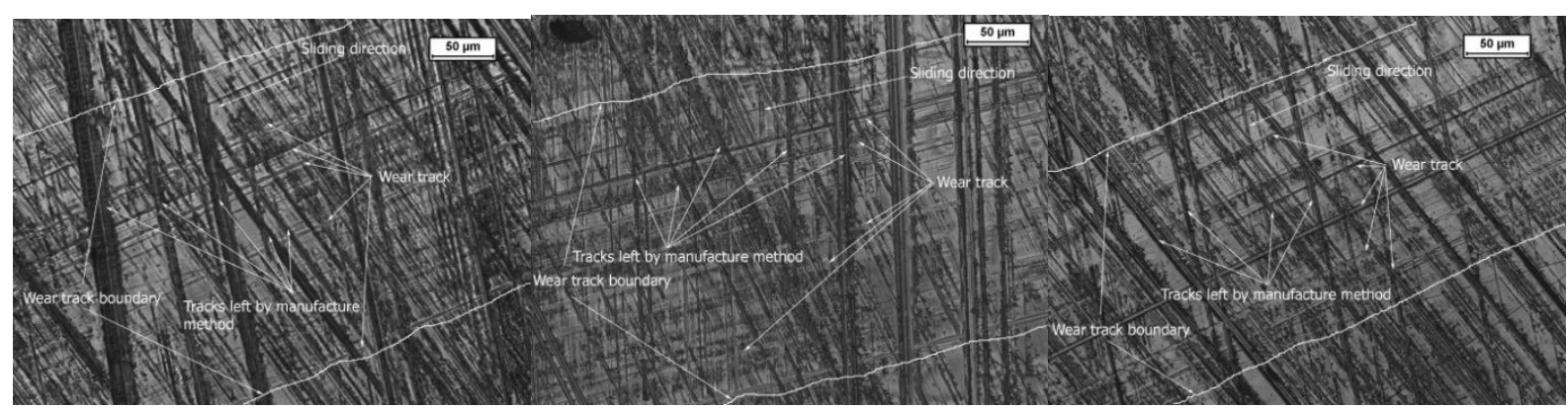
(a') AQ-AQ
(b') RS-RS
(c') Mo-Mo

Fig. 11 Micrographs of wear tracks on disc (a, b, c: disc without pre-treatment; a', b', c': disc with pre-treatment) 


\section{ACCEPTED MANUSCRIPT}

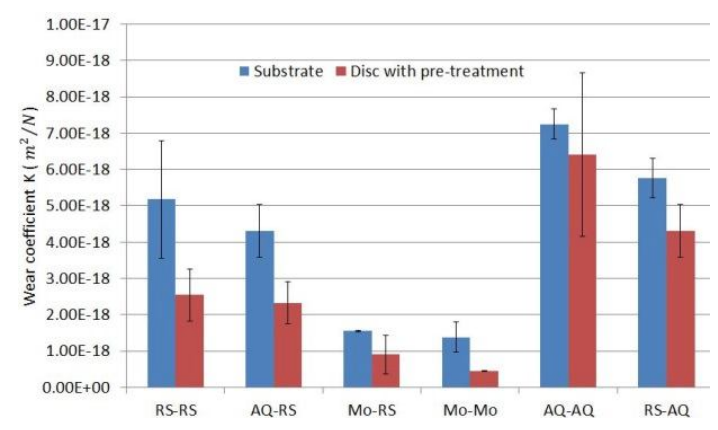

Fig. 12 Wear coefficient results in terms of mean value and standard deviation 


\section{ACCEPTED MANUSCRIPT}

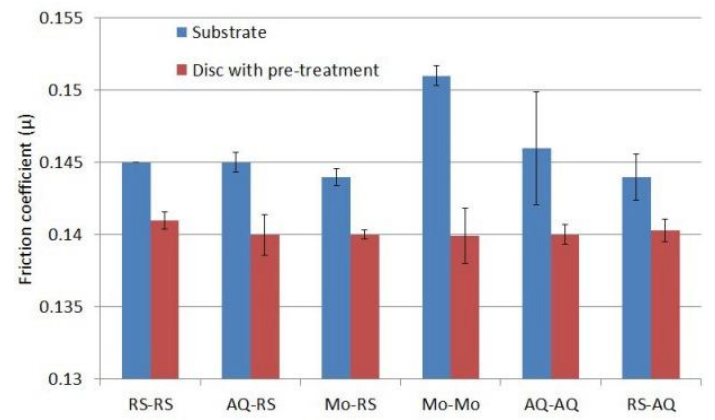

Fig. 13 Friction coefficient results in terms of mean value and standard deviation of the total experiment 


\section{ACCEPTED MANUSCRIPT}

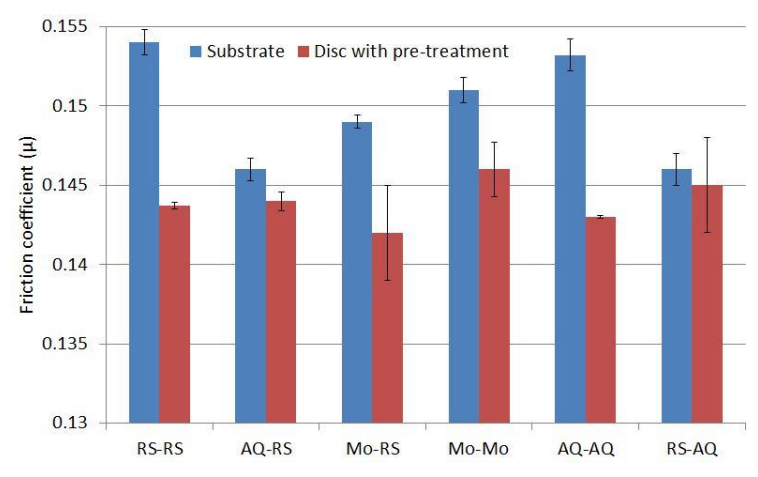

(a)

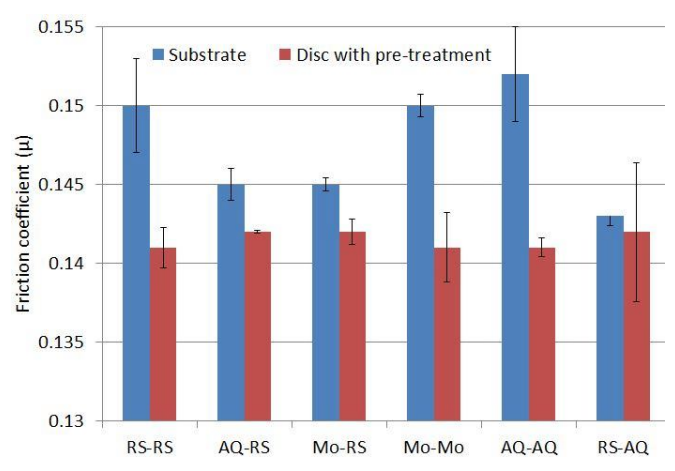

(b)

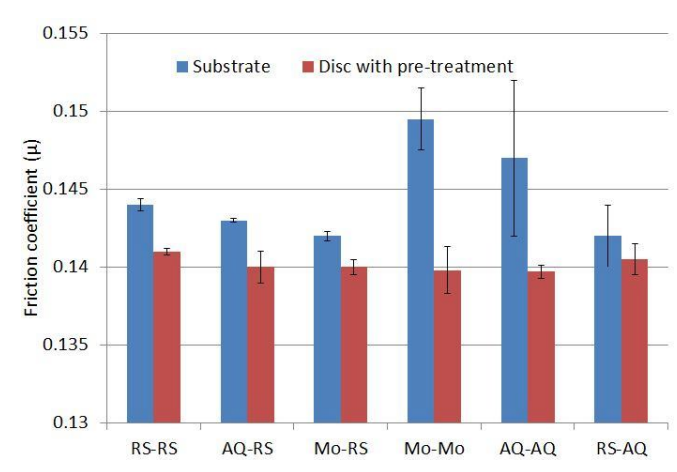

(c)

Fig. 14 Friction coefficient results in terms of mean value and standard deviation of the first five minutes (a), first stage: first hour (b), last stage: last hour (c) 


\section{ACCEPTED MANUSCRIPT}

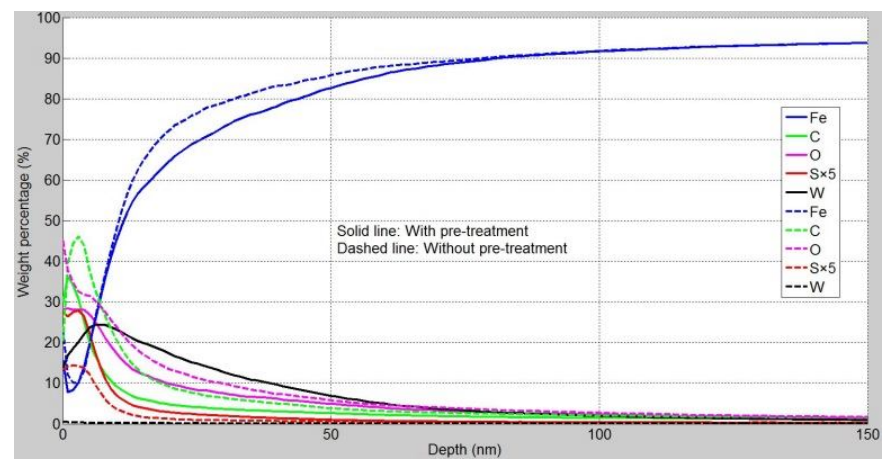

Fig. 15 GD-OES evaluated chemical composition of the tribo-film formed by pre-treatment 


\section{ACCEPTED MANUSCRIPT}

\begin{tabular}{lcccccccccc}
\hline & $\mathrm{Ni}$ & $\mathrm{Mn}$ & $\mathrm{Fe}$ & $\mathrm{C}$ & $\mathrm{S}$ & $\mathrm{P}$ & $\mathrm{Si}$ & $\mathrm{Cr}$ & $\mathrm{Mo}$ \\
\hline EN 16MnCr5 & - & $1-1.3$ & $96.95-98.78$ & $0.14-0.19$ & $\leq 0.035$ & $\leq 0.025$ & 0.4 & 1.1 & - \\
Distaloy AQ & 0.5 & 0.5 & 98.8 & 0.2 & - & - & - & - & - \\
Astaloy Mo & - & - & 98.95 & 0.2 & - & - & - & - & 0.85 \\
\hline
\end{tabular}

Table 1. Chemical composition (mass \%) of RS and AQ gear materials

\begin{tabular}{lccc}
\hline Specimen materials & RS & AQ & Mo \\
Young's modulus (GPa) & 210 & 154 & 154 \\
Poisson's ratio & 0.3 & 0.28 & 0.28 \\
\hline
\end{tabular}

Table 2. Characteristics of the specimens 


\section{ACCEPTED MANUSCRIPT}

\begin{tabular}{ll}
\hline Lubricant & BP Castrol Syntrans $75 \mathrm{~W}-80$ \\
Kinematic viscosity at $40^{\circ} \mathrm{C}(\mathrm{cSt})$ & 64.1 \\
Kinematic viscosity at $100^{\circ} \mathrm{C}(\mathrm{cSt})$ & 11.8 \\
$\left.\qquad \mathrm{~kg} / \mathrm{m}^{3}\right)$ & 837 \\
Density & 183 \\
Viscosity index, $\eta(-)$ & 300 \\
Phosphorus content (ppm) & 890 \\
Sulphur content (ppm) & GL-4 \\
API Category &
\end{tabular}

Table 3. Test Lubricant 


\section{ACCEPTED MANUSCRIPT}

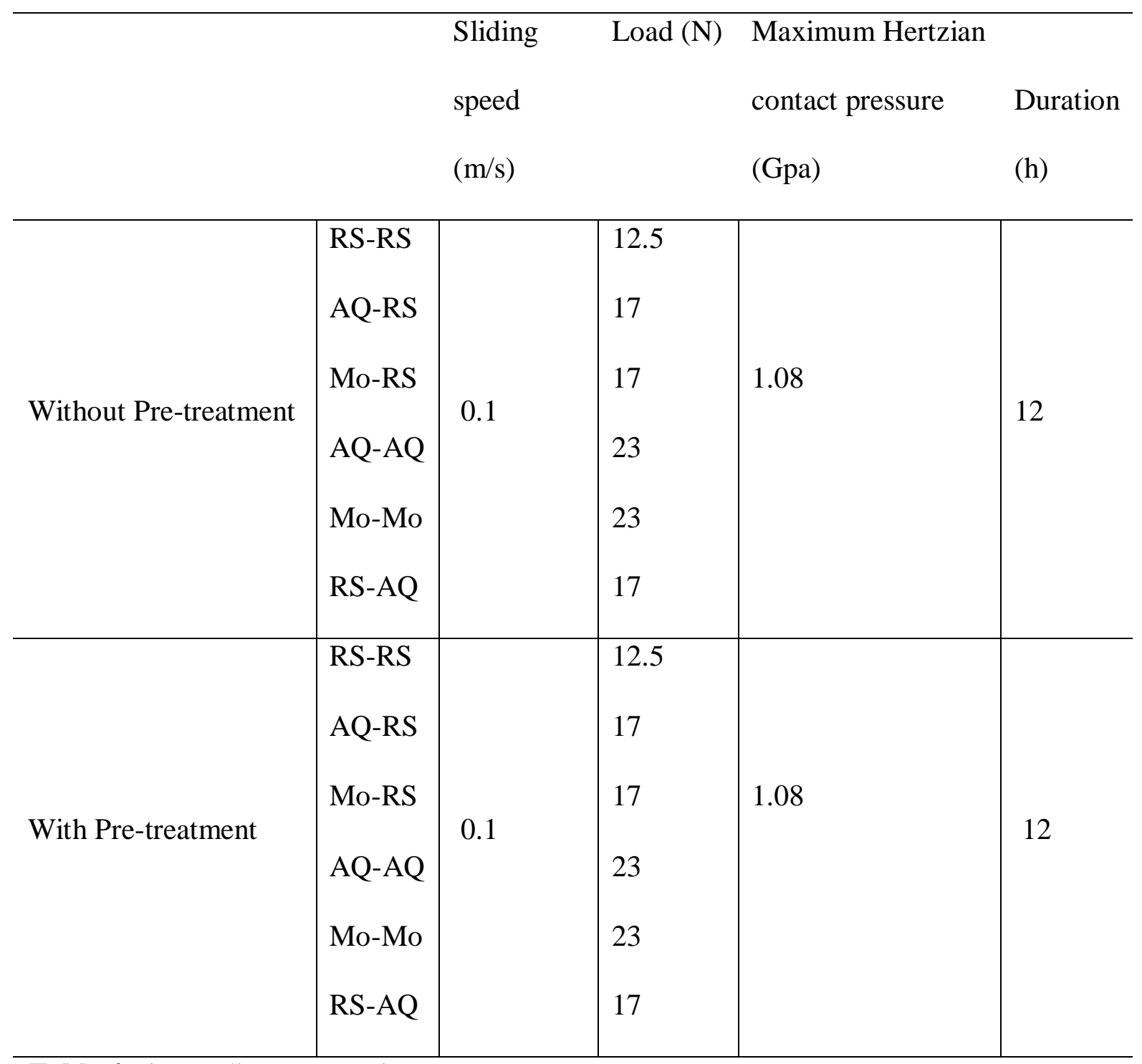

Table 4 Pin-on-disc test matrix 


\section{ACCEPTED MANUSCRIPT}

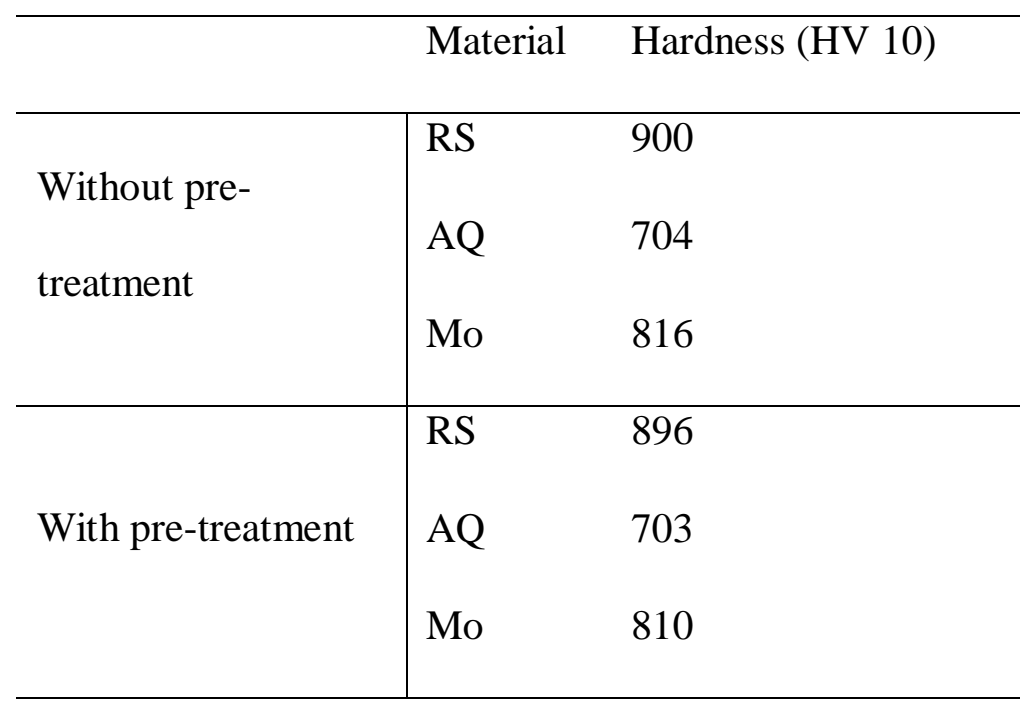

Table 5 Hardness of discs 


\section{ACCEPTED MANUSCRIPT}

\begin{tabular}{llllllll}
\hline & Material combination & RS-RS & AQ-RS & Mo-RS & Mo-Mo & AQ-AQ & RS-AQ \\
& & & & & & & \\
\hline $\mathrm{Sa}$ & Substrate & 0.25 & 0.26 & 0.25 & 0.29 & 0.3 & 0.21 \\
\cline { 2 - 8 }$(\mu \mathrm{m})$ & Pre-treatment & 0.18 & 0.21 & 0.17 & 0.12 & 0.19 & 0.14 \\
& & & & & & & \\
\hline $\mathrm{Sz}$ & Substrate & 1.73 & 2.79 & 1.56 & 1.8 & 1.09 & 1.88 \\
\cline { 2 - 8 }$(\mu \mathrm{m})$ & Pre-treatment & 1 & 1.42 & 1.1 & 1.1 & 1.14 & 1.2
\end{tabular}

Table 6 Three dimensional surface roughness parameters for pins 


\section{ACCEPTED MANUSCRIPT}

\begin{tabular}{|c|c|c|c|}
\hline & & \multicolumn{2}{|c|}{ Wear scar diameter $(\mu \mathrm{m})$} \\
\hline & & First time & Second time \\
\hline \multirow{6}{*}{ Disc without pre- } & RS-RS & 455.5 & 409 \\
\hline & AQ-RS & 422 & 397.5 \\
\hline & Mo-RS & 317 & 318.5 \\
\hline & Mo-Mo & 361 & 323 \\
\hline & $A Q-A Q$ & 537 & 427 \\
\hline & RS-AQ & 429 & 494 \\
\hline \multirow{6}{*}{ Disc with pre- } & RS-RS & 360 & 324.5 \\
\hline & AQ-RS & 366.5 & 335.5 \\
\hline & Mo-RS & 303 & 242.5 \\
\hline & Mo-Mo & 261.5 & 257.5 \\
\hline & AQ-AQ & 520 & 410 \\
\hline & $\mathrm{RS}-\mathrm{AQ}$ & 422 & 397.5 \\
\hline
\end{tabular}

Table 7 The diameter of the wear scar of worn pin tip 


\section{ACCEPTED MANUSCRIPT}

\begin{tabular}{|c|c|c|c|c|c|c|c|}
\hline & & Whole & & & & Surface & Surface \\
\hline & Wear & friction & First five & First & Last & amplitude & amplitude \\
\hline & coefficient & coefficient & minutes & stage & stage & parameters of $\mathrm{Sa}$ & parameters of $\mathrm{Sz}$ \\
\hline$p_{T}$ & 0.0064 & 0.0044 & 0.0148 & 0.01 & 0.005 & 0.0034 & 0.018 \\
\hline$p_{n}$ & 0.0007 & 0.59 & 0.607 & 0.73 & 0.475 & 0.39 & 0.21 \\
\hline
\end{tabular}

Table 8 The ANOVA results of wear coefficients, friction coefficients and pin surface amplitude parameters $\mathrm{Sa}$ and $\mathrm{Sz}$ 